\title{
Balanced scorecard em uma empresa do ramo de transporte revendedor retalhista
}

A crescente necessidade de mudanças e inovações no mundo econômico resultou com que as organizações busquem cada vez mais diferentes formas de alcançarem melhor desempenho e destaque no mercado. O foco desta pesquisa é o Balanced Scorecard-BSC, uma ferramenta de gestão estratégica que permite à empresa a medição e o aumento de seu desempenho através de indicadores. O objetivo é propor para uma empresa do ramo de transportador revendedor retalhista-TRR um modelo de Balanced Scorecard, elaborado de acordo com sua estrutura organizacional. A metodologia enquadra-se como descritiva, estudo de caso e o método de abordagem foi dedutivo e qualitativa. Na fundamentação teórica discorreu-se sobre: planejamento estratégico, estratégia empresarial, modelo de Porter, o BSC e suas quatros perspectivas, mapas estratégicos e TRR. A coleta de dados foi realizada por meio de reuniões com os responsáveis pela empresa, através das quais foram fornecidas informações que proporcionaram a criação do modelo proposto. Diante da criação do modelo de BSC se verificou que os procedimentos necessários não diferem dos procedimentos ditados pelos criadores Kaplan e Norton, há necessidade de desenvolver a premissa da criação da missão, visão e valores, e posteriormente a estratégia empresarial e os indicadores sob o enfoque nas quatros perspectivas deste modelo.

Palavras-chave: Balanced Scorecard-BSC; Ferramenta de gestão; Transportador Revendedor Retalhista-TRR.

\section{Balanced scorecard in a retail transport branch company}

The growing need for change and innovation in the economic world has meant that organizations are increasingly looking for ways to achieve better performance and market prominence. The focus of this research is the Balanced Scorecard-BSC, a strategic management tool that allows the company to measure and increase its performance through indicators. The objective is to propose to a TRR retail carrier carrier a Balanced Scorecard model, elaborated according to its organizationa structure. The methodology fits as descriptive, case study and the approach method was deductive and qualitative. The theoretical foundation discussed: strategic planning, business strategy, Porter's model, BSC and its four perspectives, strategic maps and TRR. Data collection was performed through meetings with those responsible for the company, through which information was provided that provided the creation of the proposed model. Given the creation of the BSC model it was found that the necessary procedures do not differ from the procedures dictated by the creators Kaplan and Norton, it is necessary to develop the premise of the creation of the mission, vision and values, and later the business strategy and the indicators under the focus on the four perspectives of this model.

Keywords: Balanced Scorecard-BSC; Management tool; Retail Reseller Carrier-TRR.

Topic: Planejamento, Estratégia e Competitividade

Reviewed anonymously in the process of blind peer
Received: 15/03/2020

Approved: 01/04/2020
João Bosco Arbués Carneiro Júnior (in

Universidade Federal de Mato Grosso, Brasil

http://lattes.cnpq.br/5073023761658236

http://orcid.org/0000-0001-7094-2245

ibacj@hotmail.com

Nayra Angélica de Oliveira

Universidade Federal de Rondonópolis, Brasil

http://orcid.org/0000-0002-6593-7588

nayra angelica@hotmail.com

Sofia Inés Niveiros (iD

Universidade Federal de Rondonópolis, Brasil

http://lattes.cnpq.br/0047857963186064

http://orcid.org/0000-0001-6547-5881

sniveiros@hotmail.com

\section{Referencing this:}

CARNEIRO JÚNIOR, J. B. A.; OLIVEIRA, N. A.; NIVEIROS, S. I.. Balanced scorecard em uma empresa do ramo de transporte revendedor retalhista. Revista Brasileira de Administração Científica, v.11, n.2, p.81-97, 2020. DOI: http://doi.org/10.6008/CBPC2179$\underline{684 X .2020 .002 .0006}$ 


\section{INTRODUÇÃO}

As organizações estão inseridas em um ambiente econômico cada vez mais competitivo e criativo, resultado do crescimento acelerado de organizações que iniciou na década de 1990 com a era da informação e a globalização. Desta forma a competitividade tornou-se um grande desafio para as empresas e sobreviver no mercado passou a requerer estratégias com eficiência e eficácia. Como solução de sobrevivência neste cenário altamente competitivo, as empresas necessitaram formatar novas formas de controle gerencial. A importância de introduzir e controlar com eficácia um planejamento estratégico passou a ser indispensável para o crescimento e sustentação no mercado (MOTTA, 1995; CHIAVENATO, 2005; CORSATTO et al., 2013; BERTAGLIA, 2017).

As organizações perceberam que é preciso buscar novas ferramentas com o intuito de auxilia-las no aumento do desempenho organizacional. As empresas de Transportadores Revendedores Retalhistas-TRRs, também enfrentam esse cenário e necessitam de soluções para a situação. Os TRRs são autorizados pela Agência Nacional do Petróleo, Gás Natural e Biocombustíveis - ANP a revender menores quantidades de combustível, adquiridos a granel, óleo lubrificante acabado e graxa envasados. Eles também são responsáveis pelo armazenamento e transporte do produto.

Segundo Lima (2007) os TRRs podem revender combustível a retalho: (a) com entrega em ponto de abastecimento localizado no domicílio do consumidor; (b) para abastecimento direto de máquinas e veículos de consumidor que possuam restrição de locomoção, dificuldades operacionais ou que estejam em locais de difícil deslocamento; e (c) para abastecimento de embarcações marítimas ou fluviais; e óleo lubrificante acabado e graxa envasados.

Um ramo de atividade que possui relevância no estado de Mato Grosso é o TRR, pois possui como principais clientes os produtores rurais os quais utilizam de combustíveis para abastecimento de máquinas agrícolas. Segundo Instituto Brasileiro de Geografia e Estatística-IBGE (2017) o estado de Mato Grosso lidera a produção de grãos do país. Desta forma, a empresa está localizada em um estado que possui grande possibilidade de captação de clientes. Um dos maiores desafios que as TRRs podem enfrentar são qualidade e garantia dos produtos, rapidez e segurança na entrega e também o preço competitivo, quesitos que quando não trabalhados como plano estratégico podem influenciar no desempenho organizacional ocasionando perdas significativas.

Em 1992, os professores da Harvard Business School, Norton e Kaplan desenvolveram o Balanced Scorecard-BSC, que é um sistema de medidas de desempenho, que considera as necessidades das organizações em sentido amplo, representando suas estratégias com a finalidade de promover integração com toda a organização, através de indicadores baseado nas perspectivas: financeiras, de clientes, de processos internos e aprendizagem e inovação. Kaplan et al. (1997) definem o BSC como um sistema de gestão estratégica para administrar a estratégia em longo prazo. Niven (2003) identificou que aproximadamente $50 \%$ das empresas cotadas no Fortune 1000 , obtiveram sucesso na implementação do $B S C$, concluindo que o modelo assume um papel relevante para organizações de grande e pequeno porte, 
sejam públicas, privadas ou sem fins lucrativos.

A maioria das organizações almeja o aumento dos lucros e redução dos custos para alcançar o sucesso empresarial, dependem da integração de todos os setores para produzirem em conjunto à eficácia empresarial. Este assunto é importante para um gerenciamento de qualidade nas atividades das organizações, dentro deste contexto a presente pesquisa pretende responder a seguinte questão: quais procedimentos devem ser utilizados para a implantação do Balanced Scorecard - BSC - em uma empresa do ramo de transportador revendedor retalhista-TRR como ferramenta de gestão empresarial? O objetivo deste trabalho consiste em propor um modelo de sistema de planejamento estratégico baseado no Balanced Scorecard para uma empresa atuante no mercado de Transportador Revendedor Retalhista do município de Rondonópolis.

Atuam no país como TRR, 462 empresas (ANP, 2017). No estado de Mato Grosso estão presente 54 TRRs atuantes reguladas pela ANP, a pesquisa será realizada na cidade de Rondonópolis, localizada na região sul do estado de Mato Grosso, que possui 4 TRRs. A proposta de BSC apresenta como objeto de estudo uma das quatro empresas de TRR situada em Rondonópolis. A TRR em estudo está sediada na cidade há 24 anos, de início como uma filial e um ano depois como matriz. A empresa conta com um quadro de 29 funcionários e a ela compete a revenda de óleo diesel no estado de Mato Grosso.

O cenário competitivo exige das empresas mudanças nos processos de gestão, desta forma, o ato de planejar é crucial para um bom gerenciamento nas organizações. Considerando a carência de planejamento estratégico existentes nesta modalidade de atividade econômica e por se tratar de um assunto de elevado interesse das organizações esta pesquisa justifica-se pela necessidade de mudanças e inovações no mercado econômico da cidade de Rondonópolis no setor de TRR. O estudo será de grande valia quanto suposta e esperada aplicabilidade que acarretará o aumento de seu desempenho e consequentemente a criação de valor, que lhe proporcionará também o reconhecimento de seus clientes.

\section{REVISÃO TEÓRICA}

\section{Planejamento Estratégico}

As organizações buscam ser competitivas no mercado e para isso procuram ter um diferencial que agregue valor em suas atividades ou produtos. Uma importante ação para Ihes proporcionar um melhor desempenho e o alcance dos objetivos almejados é o planejamento. Ter conhecimento de informações relevantes para suas tomadas de decisões e processar objetivos para se alcançar o sucesso pretendido é um dos aspectos mais importante para as organizações.

Planejar é determinar o caminho a ser seguido com o objetivo de alcançar resultados almejados atingindo o sucesso nas ações desempenhadas. O Planejamento representa uma das formas mais significantes de melhoria de qualidade nas ações decisórias dos gestores, pois opera como uma ferramenta de análise de futuras situações da empresa (GOMES et al., 2015).

Para determinar a direção mais proveitosa a ser seguida pela organização é recomendado elaborar 
um Planejamento Estratégico, com o objetivo de aproveitar as oportunidades e evitar as ameaças (FISCHMANN et al., 2009; OLIVEIRA, 2013). Por conseguinte, é evidente que empresas que possuem o planejamento estratégico conquistam um melhor desempenho em relação às demais organizações (CHIAVENATO et al., 2009).

Para um melhor entendimento destaca-se a pesquisa realizada por Rocha et al. (2011) que procurou demonstrar quais os fatores encontrados na literatura que indicam o BSC como um instrumento que facilita o processo de planejamento e controle nas empresas. Através de um estudo ilustrativo, que funciona como um guia prático, utilizando 71 artigos coletados nos anais eventos e periódicos da área de Administração, Ciências Contábeis e Turismo, com base na relação do Qualis/Capes do triênio de 2007/2009, o referido trabalho constatou que o BSC pode ser entendido como instrumento que facilita o processo de planejamento e controle nas empresas. Também, foi possível entender que a existência de um planejamento estratégico dentro das organizações facilita a implantação do BSC.

Ainda sobre o planejamento estratégico, pode-se afirmar que este consiste em relacionar os objetivos das organizações abrangendo-a como um todo, ou seja, de forma interagida e combinada envolvendo todos os setores na formação dos planos estratégicos (RENESTO, 2008). Assim, o planejamento estratégico deve sob a ótica geral da organização estabelecer planos de ações necessárias para uma tomada de decisão adequada. Estes planos são definidos através de perguntas fundamentais, que produzem respostas auxiliadoras às ações a serem seguidas. Como auxilio ao planejamento estratégico, o $B S C$ é uma ferramenta de grande importância na construção de um sistema de gestão estratégica das empresas.

\section{Estratégia Empresarial}

A estratégia empresarial compreende um importante instrumento de orientação às organizações para obterem o norteamento das ações que devem ser executadas. Estratégia consiste no estudo das informações da situação presente e a definição de ações com a finalidade de promover mudanças. Kaplan et al. (1997) destacam como estratégia a definição dos segmentos de mercado e clientes em que se pretende atuar, quais processos internos considerados críticos devem ser priorizados para alcançar a excelência e entregar valor aos clientes, considerando os objetivos internos e as capacidades individuais e organizacionais. Os autores ainda definem a estratégia como um conjunto de hipóteses sobre causas e efeitos, que o BSC deve evidenciar através de suas perspectivas (KAPLAN et al., 1997).

Esta relação de causas e efeitos estabelece a compreensão de 'como fazer' para alcançar os objetivos pretendidos. Pois, podem ser observadas quais as consequências que determinadas ações trariam às organizações, partindo da análise dos possíveis benefícios a serem obtidos.

Por se tratar da contribuição do BSC à evidenciação das estratégias empresarias Schimidt et al. (2012) apresentaram a importância do BSC como ferramenta estratégica e competitiva aplicável a uma distribuidora de combustíveis, se caracterizando estudo de caso. A pesquisa dos autores buscou oferecer uma proposta de implantação do BSC que atendesse as expectativas gerenciais da empresa, por meio da revitalização do planejamento estratégico que se encontrava descontinuado. Como conclusão, obteve-se o aprimoramento 
do modelo de gestão, e a identificação do $B S C$ como sendo mais que um sistema de medição de desempenho e sim um sistema gerencial, pois além de medir o desempenho, o BSC orienta na identificação dos objetivos estratégicos, facilitando a tradução destes objetivos a toda organização.

Para Costa (2008) a estratégia de uma empresa pode ser um processo ou um plano de ação, mas em ambos os focos os requisitos básicos são: a coleta, a organização e a utilização de recursos de forma a ajudar a empresa a alcançar seus objetivos, tornando-a competitiva. $O$ entendimento de estratégia como vantagem competitiva é estabelecido por meio da alavancagem que está proporciona às empresas, fazendo com que organizações que possuem estratégias conquistem melhores resultados em relação aos seus concorrentes.

O desenvolvimento da estratégia empresarial inicia-se através da definição da missão, visão e valores das organizações, posteriormente aprimora seus planos de ações e estabelece metas a serem seguidas. As metas devem obedecer a capacidades dos recursos internos e a identificação do mercado externo, com a intenção de conquistar a maximização dos resultados almejados. Desta forma, quando a estratégia é bem elaborada e transmitida com facilidade de compreensão a toda a organização, faz com que a empresa conquiste melhores resultados e reconhecimento no mercado. Neste contexto, para Porter (1989) "A estratégia competitiva visa estabelecer uma posição lucrativa e sustentável contra as forças que determinam a concorrência na indústria".

Deste modo a essência da elaboração das estratégias competitivas está relacionada ao ambiente econômico que as organizações estão inseridas, e devem observar a influência das cinco forças competitivas (PORTER, 2004). Esse modelo é utilizado com a finalidade avaliar o grau de concorrência de um determinado mercado econômico. Porter (2004) em relação as cinco forças afirmam que determinam o potencial de lucro final, que é medido em termos de retorno a longo prazo sobre o capital investido. As cinco forças são: ameaças de novos entrantes, poder de negociação dos compradores, ameaça de produtos ou serviços substitutos, poder de negociação dos fornecedores e rivalidade entre as empresas existentes (PORTER, 2004).

Algumas táticas podem ser utilizadas para se obter esta posição no mercado, sendo estas: "concorrências de preços, batalhas de publicidade, introdução de produtos e aumento dos serviços ou das garantias ao cliente" (PORTER, 2004). Desta forma, o modelo de Porter permite às empresas a realização de analises a fim de identificar quais seus pontos fortes e fracos para assim estabelecerem estratégias competitivas, com a finalidade de obter resistências às forças competitivas.

\section{Balanced Scorecard}

Criado em 1990, nos Estados Unidos, por Kaplan e Norton, como um sistema de medição de desempenho, o Balanced Scorecard-BSC era definido como ferramenta de suporte que permitia os gestores a analisarem a organização a fim de mensurar seu real desempenho. A criação do BSC se motivou devido à percepção de que apenas os métodos apoiados por indicadores contábeis e financeiros eram insuficientes para oferecer suporte às organizações. Com a intenção de inovar os modelos de medição de desempenho já as primeiras implantações do BSC apresentaram resultados satisfatórios. Logo, os criadores do BSC 
perceberam que não se tratava apenas de um sistema de medição de desempenho, mas sim de um sistema de gestão estratégica (KAPLAN et al., 1997; 2000).

A ampliação do BSC proporcionou então para as empresas, o alinhamento de suas medidas à estratégia organizacional, através do gerenciamento das mesmas. Segundo Schmidt et al. (2012) o BSC se origina da estratégia da empresa e através dela a empresa atingirá sua missão e seus objetivos estratégicos. O BSC proporciona aos gestores das organizações ferramentas necessárias para o alcance do sucesso pretendido (KAPLAN et al., 1997; CREPALDI, 2012). Esse auxílio é fundamental nos dias atuais partindo da complexidade do mercado econômico. Percebe-se, portanto que esse sistema de gestão estratégia permite além da mensuração e acompanhamento do desempenho, o monitoramento das ações executadas, a fim de ajustá-las de acordo com as estratégias anteriormente determinadas.

O método utilizado no BSC para medir e gerenciar o desempenho organizacional está alicerçado em indicadores, pois permitem a comparação das ações executadas com os objetivos estratégicos determinados. A utilização de indicadores financeiros não é suficiente para orientar e avaliar o desempenho da organização, pois retrata apenas parte da história das ações desenvolvidas e não oferecem suporte às futuras tomadas de decisões (KAPLAN et al., 1997). O BSC possui não apenas indicadores financeiros, mas também indicadores não financeiros que permitem o equilíbrio de sistema de gestão, ofertando os resultados do desempenho passado que podem servir para análises de comparação e também o auxílio quanto à prevenção situações futuras, ajudando a planejar melhores métodos de tratar à essas situações.

Com relação à colaboração do BSC ás organizações, a pesquisa de Lunkes et al. (2009) busca investigar qual é a contribuição da utilização do BSC para uma empresa de software, caracterizando a pesquisa como sendo um estudo de caso. A pesquisa ainda obteve a coleta de informações por meio de reuniões gerenciais onde definiram a utilização do Balanced Scorecard como ferramenta de suporte às tomadas de decisões uma vez que a utilização de apenas ferramentas voltadas a dados financeiros e contábeis já não atendiam a necessidade dos gestores da organização. Por fim, através da elaboração do planejamento estratégico, e consequentemente mapas estratégicos, indicadores, metas, iniciativas estratégicas do negócio e a comunicação e implementação do BSC a empresa construiu o seu sistema de gestão e os autores sugeriram trabalhos futuros para acompanhamento do BSC com o objetivo de constatar suas contribuições e vantagens de implantação. Além dos benefícios, conforme Kaplan et al. (1997) "o verdadeiro poder do BSC, todavia, ocorre quando deixa de ser um sistema de medidas e se transforma em um sistema de gestão estratégica".

Na pesquisa de Galas et al. (2006) o objetivo foi analisar os impactos da implantação do BSC nos fatores de alinhamento estratégico da TI com o negócio, sob a perspectiva dos gestores. Foi uma pesquisa exploratório-qualitativa, por meio de um estudo de casos múltiplos em empresas que implantaram o BSC e que possuem área de TI. As fontes de evidências foram: entrevistas focais, questionário semiestruturado, documentos e observação direta. Os resultados mostram que a implantação do BSC provoca mudanças gerenciais que influenciam nos fatores do alinhamento da TI das quatro categorias, transformando-os em fatores facilitadores do alinhamento e contribuindo positivamente para o alinhamento da TI com o negócio. 
Sobre os benefícios desse sistema, ainda se pode complementar na visão de Crepaldi (2012) que organizações que utilizam do BSC se tornam mais ágil e proativa controlando melhor as mudanças ocorridas no ambiente interno e externo, criando maior riqueza à organização. $\mathrm{O}$ autor também esclarece sobre a possibilidade que esse sistema traz para analises das estratégias, cumprimento de missão, sob as diversas perspectivas abrangentes do BSC, a fim de verificar se os planos de ações estão sendo executados de acordo com as estratégias, por fim o autor ainda descreve sobre a importante vantagem desse sistema como estratégia empresarial até ao ponto que ele aumenta os resultados.

A elaboração do BSC deve, portanto, servir como auxilio no desenvolvimento da mesma, também é preciso que este sistema seja elaborado de acordo com a situação real de cada organização obedecendo a suas particularidades e também seus próprios objetivos (KAPLAN et al., 2000). Com relação aos indicadores, estes são definidos de acordo com as quatro perspectivas determinadas pelo BSC, estas são: Financeira, Clientes, Processos Internos e de Aprendizado e Crescimento.

\section{Perspectiva de aprendizagem e crescimento}

Esta é uma das perspectivas não financeiras, estabelecidas pelo BSC, ela desenvolve medidas e objetivos com a finalidade de orientar o aprendizado e crescimento das organizações. Estes objetivos devem orientar as empresas em relação à identificação do que precisa ser melhorado para se obter um melhor desempenho e preparação para os possíveis futuros cenários que as empresas possivelmente irão enfrentar. Kaplan et al. (1997) descrevem que esta perspectiva "identifica a infraestrutura que a empresa deve construir para gerar crescimento e melhoria a longo prazo".

O crescimento das empresas está relacionado com a criação de valor que as mesmas conseguem conquistar. A criação de valor de uma organização depende do seu capital humano, do conhecimento e dos meios pela qual esse conhecimento é compartilhado (KAPLAN et al., 1997). Os indicadores da perspectiva de aprendizado e crescimento apresentam como a empresa pode crescer e ainda especifica que esta perspectiva tem como importantes indicadores: nível de satisfação, rotatividade, lucratividade, capacitação e treinamento e participação dos funcionários, com sugestões para redução de custos ou aumento de receitas (CREPALDI, 2012).

Neste contexto a importância dos indicadores sob a perspectiva de aprendizagem e crescimento pode ser vista na pesquisa de Freire et al. (2010) que analisaram quais fatores de clima organizacional, referendados na literatura do $B S C$, necessitam uma maior atenção por parte dos gestores dos hotéis de pequeno e médio porte da cidade de Campina Grande/PB para obtenção de êxito na gestão empresarial. As autoras utilizaram uma amostra de sete hotéis e coletaram os dados através da aplicação de questionários. Concluíram que os fatores que necessitam de maior atenção são, por ordem de significância: estilo de gerência, reconhecimento, entusiasmo, apoio e autonomia e por último recompensa e inovação. Percebe-se que os fatores estabelecidos pelas autoras, são associadas às características necessárias para a conquista do êxito na implementação da estratégia sob a ótica das perspectivas de aprendizado e crescimento do BSC. Portanto, foi demonstrada a importante necessidade do gerenciamento dos objetivos estabelecidos sob a 
perspectiva que se torna essencial para criação de valor da empresa e é parte indispensável para alcançar os resultados desejados, considerando que seus colaboradores são classificados como intermediários para o alcance do sucesso. Em função do exposto, acredita-se que o investimento em pessoas proporciona maior eficiência e auxilia no crescimento da organização, por meio da maximização de qualidade nas funções desempenhadas, redução de custos com rotatividade e acrescente qualificação dos profissionais.

\section{Perspectiva de processos internos}

Nesta perspectiva de processos estão definidos indicadores de caráter não financeiros e estes estão direcionados ao ambiente interno da organização. Assim, devem ser identificados pelos gestores, quais os processos que necessitam de melhorias para alcançar a excelência. Para Kaplan et al. (1997) "as medidas dos processos internos estão voltadas para os processos internos que terão maior impacto na satisfação do cliente e na consecução dos objetivos financeiros da empresa".

Nessa mesma perspectiva, Gomes et al. (2010) afirmam que aos processos internos é importante introduzir melhorias e uma maior flexibilização nos processos existentes de forma a criar valor para os clientes, logo esta perspectiva também deve integrar a estrutura do BSC. As empresas devem identificar quais os processos internos estão falhos, para se obter a concretização dos objetivos. Segundo Kaplan et al. (1997) a derivação de objetivos e medidas para esta perspectiva é o que difere o BSC de outros sistemas tradicionais de medição de desempenho, eles visam o controle e a melhoria dos centros de responsabilidade e departamento existente e dependem exclusivamente de medidas financeiras e relatórios de variação para controlar as operações, diferente do BSC que busca medidas de custos, qualidade, produtividade e tempo para avaliar os processos.

Os processos internos são um fator chave no sucesso financeiro. As atividades englobam processo de inovação, operacional e de serviços pós-venda, ou seja, desde a identificação das necessidades até a satisfação dos clientes (CREPALDI, 2012; KAPLAN et al., 1997). Estes processos apresentam o objetivo de atender as necessidades dos clientes, porém essas medidas também contribuem para a conquista de excelência interna da organização, pois as melhorias direcionadas aos clientes proporcionam a empresa criação de valor e consequentemente maximização dos resultados.

\section{Perspectiva de clientes}

Nesta perspectiva estão considerados os indicadores não financeiros que visam o mercado externo, a fim de identificar o nível de satisfação dos clientes. Devem ser definidos através desta perspectiva segmentos que constituem a origem dos objetivos financeiros. Segundo Kaplan et al. (1997) esta perspectiva "permite que as empresas alinhem suas medidas essenciais de resultados relacionadas aos clientessatisfação, fidelidade, retenção, captação e lucratividade- com segmentos específicos de clientes e mercado". Ainda segundo estes autores esta perspectiva identifica e avalia de forma clara as propostas de valor dirigidas a esses segmentos.

É importante especificar os segmentos dos clientes e mercados, pois os mesmos não possuem 
características homogêneas e tendem a valorizar os atributos de um determinado produto ou serviço sob diferentes formas. Elas devem definir sua missão e estratégia estabelecendo objetivos específicos com base no mercado e nos clientes nos quais preferem atuar (KAPLAN et al., 1997).

Após a etapa da identificação dos segmentos de clientes e mercado, as entidades devem atentar-se aos objetivos e indicadores. De acordo com Costa (2008) é necessário articular os objetivos e as metas com atributos, tais como tempo, qualidade, desempenho e também serviço e preço e traduzi-los em medidas especificas. Kaplan et al. (1997) caracterizaram esses atributos em três categorias: serviço/produto; relacionamento com o cliente; e imagem e reputação. O primeiro diz respeito a sua funcionalidade, seu preço e sua qualidade, o relacionamento com o cliente diz respeito à entrega do produto ou serviço e a imagem e reputação dizem respeito ao modo como a empresa se apresenta para seus clientes.

Desta forma, é preciso que as empresas realizem pesquisas de mercados com a pretensão de identificar quais as preferências de seus clientes e mercados. A partir desta mensuração, são também permissíveis que as empresas identifiquem quais são seus pontos falhos em relação aos clientes e as possíveis formas de melhorar. Fica evidente, portanto, que empresas que compreendem as necessidades de seus clientes e trabalham em função de satisfazer estas necessidades, possuem uma melhor posição no mercado em relação aos seus concorrentes que não se preocupam com as preferências de seus clientes.

\section{Perspectiva financeira}

A perspectiva financeira tem como objetivo direcionar a determinação de metas e objetivos que visam o crescimento de resultados financeiros dentro das organizações. As metas financeiras se relacionam com rentabilidade, crescimento e valor para os acionistas (PRIETO et al., 2006; KAPLAN et al., 1997). Para estes autores existem três temas financeiros que norteiam a estratégias das empresas: crescimento e mix de receita, redução de custos/melhoria de produtividades, utilização dos ativos/estratégia de investimento. Essas estratégias permitem ás organizações o estabelecimento de medidas financeiras, que aumentam o retorno dos ativos financeiros e físicos, e ainda estrutura a base para a elaboração das demais medidas baseadas nas outras perspectivas.

Com relação à perspectiva financeira, pode-se citar a pesquisa de Vieira (2017) que buscou investigar como o BSC tem sido utilizado para tomada de decisão no ambiente empresarial relacionado à Perspectiva Financeira, em um centro de diagnóstico, na cidade de Guarulhos. Para a realização do referido estudo de caso, o autor utilizou questionários e entrevistas. Como resultados da implantação do BSC a empresa obteve diversos benefícios dentre eles Vieira (2017) destaca: a diminuição de desperdícios, a eliminação de gargalos operacionais, o aumento da margem de contribuição, a elevação do índice de satisfação do cliente, a melhora na taxa de êxito das propostas comerciais, a entrega dos projetos, a diminuição do índice de retrabalho, o aumento de treinamentos oferecidos aos colaboradores e o crescimento da taxa ROI em relação ao ano de 2015. Ele, ainda, declara que a utilização desse sistema de medição de desempenho, proporcionou para a empresa outros benefícios como o baixo custo, amadurecimento do conhecimento sobre a empresa.

Em resumo, o $B S C$ não é definido como um conjunto de objetivos isolados e a perspectiva financeira 
oferece suporte aos demais objetivos que serão estabelecidos através das perspectivas de clientes, processos internos e de aprendizado e crescimento.

\section{Mapas Estratégicos}

Como uma ferramenta base para desenvolver o BSC, o mapa estratégico apresenta a relação das quatro perspectivas e ainda a relação de causas e efeitos. O mapa estratégico é a estrutura capaz de fornecer visualmente esta relação. Costa (2008) considera fundamental o mapa ser absorvido nas atividades diárias pelos funcionários, a sua utilização está relacionada com a facilidade de compreensão que o mesmo proporciona para o entendimento de todo os colaboradores envolvidos na organização. Esta ferramenta é eficiente por detalhar as estratégias, melhorando a clareza dos objetivos pretendidos pelo BSC.

De acordo com Lima (2009) o mapa estratégico apresenta as medidas que deverão ser tomadas para que se consigam alcançar os objetivos propostos, e os indicadores servirão para monitorar o desempenho destes resultados. Ou seja, descreve as estratégias e plano futuro da empresa, seus valores, sua missão e sua visão (LIMA, 2009). Na sequência apresenta-se um modelo de mapa estratégico desenvolvido a uma empresa distribuidora de combustíveis.

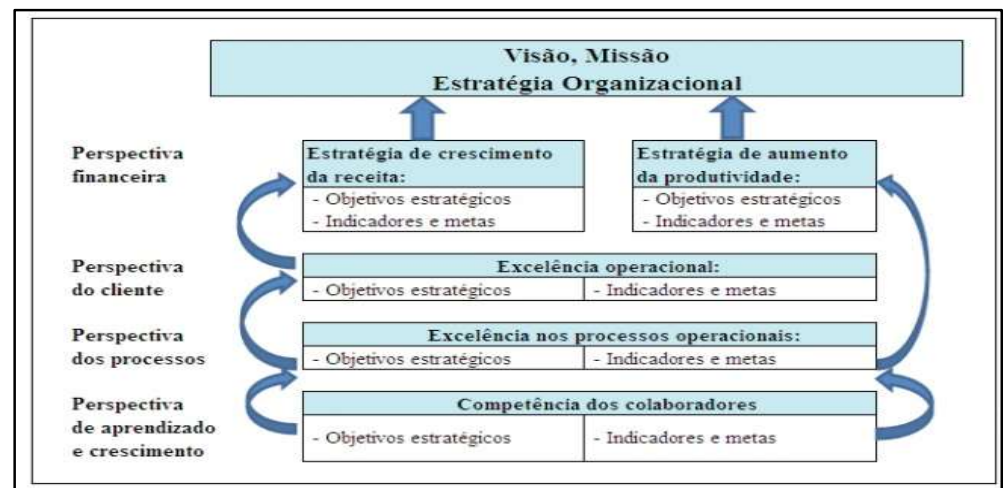

Figura 1: Modelo de Mapa Estratégico. Fonte: Kaplan et al. (1997).

No modelo acima demonstrado, estão relacionados os objetivos da empresa com as quatro perspectivas, ditadas pelos autores Kaplan e Norton, estabelecendo uma detalhada forma de interpretação das ações a serem executadas e explicando a relação entre as perspectivas. Deste modo é possível entender que a elaboração do mapa se inicia com a elaboração da missão, visão e valores das empresas, partindo das estratégias da empresa. Posteriormente deve-se então elaborar objetivos estratégicos para cada perspectiva e por fim definir os indicadores e metas. A elaboração do mapa estratégico representa a interligação das perspectivas no processo de gerenciamento.

\section{METODOLOGIA}

A metodologia da pesquisa é o detalhamento dos meios que serão utilizados para se alcançar a prática da pesquisa. Entre os quatro tipos de métodos: indutivo, dedutivo, hipotético-dedutivo e o dialético; esta pesquisa se caracteriza como dedutiva, pois parte de conceitos gerais, definidos por autores e teorias para posteriormente alcançar os casos específicos (MARCONI et al., 2010). 
Segundo Beuren (2010) a metodologia possui diferentes tipologias de delineamentos de pesquisa aplicáveis à contabilidade, sendo estes: quanto aos objetivos, quanto aos procedimentos e quanto à abordagem do problema. No que se referem os objetivos está compreendido a pesquisa exploratória, descritiva e explicativa; quanto os procedimentos abrangem estudo de caso, levantamento ou survey, pesquisa bibliográfica, experimental, documental e participante; e quanto à abordagem do problema traz a pesquisa qualitativa e quantitativa.

Esta pesquisa, com relação aos objetivos é descritiva e quanto aos procedimentos estudo de caso, pois apresenta as características de uma empresa no ramo de TRR, com a finalidade de elaborar uma proposta de implantação de $B S C$, como ferramenta de gestão empresarial. Ainda, quanto à abordagem do problema a pesquisa é compreendida como qualitativa. A coleta de dados foi realizada por meios de reuniões com os sócios proprietários e gestor da organização estudada, em forma de entrevistas estruturadas, onde o pesquisador tem por objetivo facilitar o entendimento do entrevistado.

A 1으 reunião foi realizada em 29/09/2018 ás 15:00hrs, com os proprietários e gestor da empresa estudada, onde foram utilizados, notebook, papel, caneta, nesta primeira reunião foram expostas a definição de estratégia, missão, visão e valores, onde os pesquisadores serviram como intermediadores, demonstrando a importância e função da elaboração dos pontos acima citados, através de slides explicativos.

A 2으 reunião por sua vez, foi realizada no dia 06/12/2018 às 16:30hrs onde os pesquisadores tiveram por principal objetivo a explanação das perspectivas do BSC, explicando quais são suas definições e abrangência para a determinação de indicadores. Na realização desta reunião, foram utilizados, slides explicativos através de notebook, como forma de melhorar o entendimento dos gestores, com a visualização de definições e exemplos de perspectivas para que assim posteriormente pudessem definir as próprias perspectivas com relação às necessidades da empresa.

A pesquisa é enquadrada como amostragem intencional, pois a seleção da empresa foi estabelecida por critérios de facilidade de coleta de dados na proposta de implantação do BSC, a uma empresa do ramo de TRR.

\section{RESULTADOS E DISCUSSÃO}

\section{Descrição e análises dos dados}

Este trabalho visa apresentar uma proposta de implantação do $B S C$, para uma empresa atuante no mercado de Transportador Revendedor Retalhista, com a intenção de propor um modelo de sistema de planejamento estratégico apropriado à sua estrutura organizacional, a fim de aumentar seu desempenho. Para elabora o BSC é necessário que a organização atenda alguns passos, que são considerados como base fundamental para elaboração deste. Em primeiro lugar, foi necessário que a organização possua objetivo estratégico, missão, visão e valores definidos, pois é através destes requisitos que foi realizado o embasamento para elaboração do BSC. 


\section{Estratégia}

Considerando o contexto deste estudo, através das reuniões anteriormente citadas, o gestor e o proprietário da organização apresentaram as informações descritas a seguir sobre a metodologia utilizada como estratégia empresarial. Segundo os mesmos, devido às mudanças do mercado consumidor, o TRR passou a optar por produtos de melhor qualidade, preços mais acessíveis e serviços de entrega segura e rápida. A estratégia da empresa segundo seus proprietários e gestor constitui-se em pesquisar qual tipo de Óleo Diesel melhor se enquadra nesta região e nos equipamentos dos seus clientes, adquirir produtos de qualidade junto a Distribuidoras idôneas, na aquisição do produto pesquisar o melhor preço praticado por elas. Desta forma, apresenta-se a estratégia da empresa, conforme quadro 1.

Quadro 1: Estratégia Empresarial.

\begin{tabular}{|l|l|}
\hline \multicolumn{2}{|c|}{ Estratégia } \\
\hline $\begin{array}{l}\text { Melhor Custo } \\
\text { Total }\end{array}$ & $\begin{array}{l}\text { Onde se têm a finalidade de buscar fornecedores com preços alternativos, porém que não deixem de } \\
\text { oferecer um produto de qualidade e segurança. }\end{array}$ \\
\hline
\end{tabular}

Essa estratégia se baseia no 'Melhor Custo Total', uma vez que a necessidade da empresa é a redução do preço de compra do produto, para que assim possam revender o mesmo com um valor acessível a seus clientes. A intenção é buscar vantagem na compra para poder oferecer vantagem na venda, e captar uma maior parcela de clientes através do menor preço oferecido aos mesmos.

\section{Missão, Visão e Valores}

A missão, visão e os valores, formam um conjunto de itens que fazem parte da formação dos objetivos da empresa. Esses três elementos são importantes para a empresa, eles estimulam e determinam o caminho que a empresa deve seguir para alcançar o sucesso. A missão é a razão de ser de uma organização, é o motivo pela qual a empresa existe. Cada organização deve definir e especificar sua própria missão, esta deve ser definida de forma clara e concisa para que todos possam ter conhecimento sobre ela, e principalmente para os funcionários terem a ciência de para onde a empresa deseja ir, e desta forma ajudar a conduzir está para o alcance de seus objetivos. Sendo assim, a empresa em estudo através de reuniões estruturadas, definiu a missão a qual acredita que seja a essência de sua existência.

Seguido da missão, do motivo pela qual a empresa existe, ela deve determinar qual imagem ela deseja ter no futuro. A visão se caracteriza pelas perspectivas que empresa almeja alcançar, está voltada para aquilo que a organização pretende ser no futuro. É na visão que as organizações descrevem como almejam estar em um determinado período de tempo, é sua imagem no futuro. Nela está representado o destino que a empresa pretende tornar em realidade.

Após a definição destes dois itens anteriores, é necessário definir os valores. Estes são caracterizados pelas crenças da organização, aquilo que ela acredita ser crucial para o alcance de seus objetivos. Os valores definem a ideologia da organização. Por conseguinte, o TRR em estudo definiu os três itens acima relacionados da seguinte forma, conforme o quadro abaixo apresentado. 
Quadro 2: Missão, visão e valores do TRR em estudo.

\begin{tabular}{|c|c|c|}
\hline Missão & Visão & Valores \\
\hline $\begin{array}{l}\text { Fornecer produtos e serviços de qualidade, } \\
\text { com objetivo de ter a satisfação de clientes } \\
\text { por um trabalho ágil, confiante e responsável } \\
\text { junto aos nossos clientes, manter o quadro } \\
\text { colaboradores sempre qualificados para } \\
\text { melhor atender nossa região produtora, } \\
\text { contribuindo assim com o desenvolvimento } \\
\text { regional. }\end{array}$ & $\begin{array}{l}\text { Ser um Transportador Revendedor } \\
\text { Retalhista com padrões de qualidade, } \\
\text { segurança e proteção ao meio ambiente, } \\
\text { cumprir todos os requisitos legais dos } \\
\text { órgãos que regem nossa atividade } \\
\text { comercial, sempre buscando a satisfação de } \\
\text { nossos clientes através do aprimoramento } \\
\text { dos nossos colaboradores e fornecedores. }\end{array}$ & $\begin{array}{l}\text {-Ser integrados à região em que estamos } \\
\text { estabelecidos; } \\
\text {-Ser empreendedores. Buscar sempre estar } \\
\text { entre as empresas idôneas; } \\
\text {-Ser criativo com nossa equipe de } \\
\text { colaboradores, nossos clientes e fornecedores; } \\
\text {-Fortalecer nossas parcerias diariamente; } \\
\text {-Agir da mesma forma que falamos. Sempre } \\
\text { com integridade e coerência; } \\
\text {-Valorizar a segurança, o bem-estar e a } \\
\text { qualidade de vida das pessoas; } \\
\text {-Acreditar no desenvolvimento sustentável, } \\
\text { equilibrando interesses econômico, ambiental } \\
\text { e social. }\end{array}$ \\
\hline
\end{tabular}

Após definidas a missão, a visão e os valores da organização, são necessários definir as perspectivas de acordo com o BSC. As definições dos três itens mencionados configuram a base do conhecimento de onde a empresa está e onde ela almeja chegar, para que assim torne possível a formação de estratégias com a finalidade de alcançar os objetivos desejados.

\section{Perspectivas}

De acordo com os proprietários e o gestor da organização, ficaram estabelecidos, com base na missão, na visão e nos valores, os quatros tipos de perspectivas da empresa. Conforme elaborado nos quadros a seguir foi considerada o seguinte princípio: as metas provêm das perspectivas almejadas e posteriormente norteiam as ações que sugerem com exatidão as condições precisa para concretização das perspectivas, que serão medidos pelos indicadores, que são por sua vez instrumento de gestão para medir e conduzir de forma clara e precisa as metas e objetivos da empresa, pois através deles é possível, verificar a efetivação de seus objetivos desejados.

\section{Perspectiva Financeira}

A definição da perspectiva financeira surgiu a partir da intenção dos aumentos de receitas, objetivando a redução dos custos e consequentemente a elevação dos lucros. Como meta a empresa visa à redução de custos operacionais, está economia busca a possibilidade de escolha de fornecedores com os preços menores, mas, com produtos de qualidade. Também, com o intuito de redução de custos, foi escolhida a criação de um programa de uso consciente de recursos materiais, que busca a economicidade no uso de materiais de escritório, energia, materiais de uso, consumo diário, entre outros. A ideia deste programa seria conscientizar a todos os colaboradores da importância do uso consciente destes materiais e ainda oferecer até mesmo bonificações aos mesmos quando alcançarem a diminuição destes custos.

Em relação à elevação de receitas, foi utilizado como premissa o objetivo do aumento de lucros, especificamente em $15 \%$ das receitas liquidas. As metas estabelecidas foram formadas através da necessidade de identificar quais clientes podem trazer mais lucros para empresa e a reavaliação de créditos a determinados clientes para evitar perdas com liquidação duvidosa, o qual se pode visualizar no quadro 3 . 
Quadro 3: Perspectiva Financeira.

\begin{tabular}{|c|c|c|c|}
\hline $\begin{array}{l}\text { Perspectiva } \\
\text { Financeira }\end{array}$ & Metas & Ações & Indicadores \\
\hline \multirow{2}{*}{ Reduzir Custos. } & \multirow{2}{*}{$\begin{array}{l}\text { Diminuir os custos } \\
\text { operacionais. }\end{array}$} & Buscar fornecedores alternativos. & $\begin{array}{l}\text { Redução do valor das Contas } \\
\text { com fornecedores. }\end{array}$ \\
\hline & & $\begin{array}{l}\text { Criar um programa de uso consciente de } \\
\text { recursos de materiais. }\end{array}$ & $\begin{array}{l}\text { Redução o valor de } \\
\text { pagamento. }\end{array}$ \\
\hline \multirow{2}{*}{ Elevar a Receita } & \multirow{2}{*}{$\begin{array}{l}\text { Aumentar em } 15 \% \text { a } \\
\text { receita líquida. }\end{array}$} & $\begin{array}{l}\text { Aprimorar o conhecimento na identificação } \\
\text { das vendas mais lucrativas. }\end{array}$ & $\begin{array}{l}\text { Demonstração do Resultado do } \\
\text { Exercício. }\end{array}$ \\
\hline & & $\begin{array}{l}\text { Reavaliar o prazo de concessão de crédito a } \\
\text { clientes com liquidação duvidosa. }\end{array}$ & $\begin{array}{l}\text { Demonstração do Resultado do } \\
\text { Exercício. }\end{array}$ \\
\hline
\end{tabular}

\section{Perspectiva de Processos Internos}

As perspectivas de processos internos foram definidas a partir da necessidade de melhorias nos processos que ligam o produto até o cliente. Com a redução do tempo de entrega do produto, espera-se minimizar os atrasos por falhas operacionais e assim levar o produto até o cliente em tempo hábil. A qualidade no atendimento foi definida pela importância de manter a satisfação e fidelidade dos clientes. Por fim, obter a qualidade total foi definido através da necessidade de possuir um parque de depósito de mercadorias com qualidade e segurança, com a intenção de reduzir custos com reparos. As premissas das metas desta perspectiva foram definidas com a intenção de fortificar as atividades operacionais, as que se podem observar no quadro 4.

Quadro 4: Perspectiva de Processos Internos.

\begin{tabular}{|l|l|l|l|}
\hline \multicolumn{1}{|c|}{$\begin{array}{c}\text { Perspectiva de Processos } \\
\text { Internos }\end{array}$} & \multicolumn{1}{|c|}{ Metas } & \multicolumn{1}{c|}{ Ações } \\
\hline $\begin{array}{l}\text { Melhoria no planejamento } \\
\text { de entrega de mercadoria. }\end{array}$ & $\begin{array}{l}\text { Diminuir o tempo de } \\
\text { entrega do produto. }\end{array}$ & $\begin{array}{l}\text { Implantar um sistema de } \\
\text { entrega de produtos com mais } \\
\text { rapidez. }\end{array}$ & $\begin{array}{l}\text { Diminuição entre a data do } \\
\text { pedido e a data de entrega do } \\
\text { produto. }\end{array}$ \\
\hline $\begin{array}{l}\text { Qualidade e eficiência no } \\
\text { atendimento aos clientes. }\end{array}$ & $\begin{array}{l}\text { Ter qualidade no } \\
\text { atendimento. }\end{array}$ & Oferecer treinamento. & Baixo índice de perda de clientes. \\
\hline Controle de qualidade. & Possuir qualidade total. & $\begin{array}{l}\text { Manutenção periódica no } \\
\text { parque de depósito de } \\
\text { mercadorias. }\end{array}$ & $\begin{array}{l}\text { Diminuição com reparos nos } \\
\text { depósitos de mercadorias. }\end{array}$ \\
\hline
\end{tabular}

\section{Perspectiva de Clientes}

A formação das perspectivas de clientes teve como foco em três pontos, (i) na conquista de novos clientes, (ii) na fidelização dos clientes e (iii) no desejo de ser referência no mercado de revenda do produto óleo diesel na cidade em que a empresa está situada.

Quadro 5: Perspectiva de Clientes.

\begin{tabular}{|l|l|l|l|}
\hline \multicolumn{1}{|c|}{ Perspectiva de Clientes } & \multicolumn{1}{c|}{ Metas } & \multicolumn{1}{c|}{ Indĩáes } \\
\hline Conquistar novos clientes. & $\begin{array}{l}\text { Aumentar a cartela de } \\
\text { clientes. }\end{array}$ & $\begin{array}{l}\text { Melhorar o serviço } \\
\text { prestado e o produto. }\end{array}$ & Índice de clientes. \\
\hline Fidelizar os clientes amigos. & $\begin{array}{l}\text { Permanecer com os } \\
\text { clientes antigos. }\end{array}$ & $\begin{array}{l}\text { Implantar um serviço pós- } \\
\text { vendas. }\end{array}$ & $\begin{array}{l}\text { Índice de reclamações de } \\
\text { clientes. }\end{array}$ \\
\hline $\begin{array}{l}\text { Ser referência no mercado de } \\
\text { revenda de óleo diesel. }\end{array}$ & $\begin{array}{l}\text { Tornar-se referência no } \\
\text { mercado. }\end{array}$ & $\begin{array}{l}\text { Reavaliar o sistema de } \\
\text { gestão. }\end{array}$ & $\begin{array}{l}\text { Elevado índice de } \\
\text { participação de mercado. }\end{array}$ \\
\hline
\end{tabular}

A conquista de novos clientes pretende-se realizar através de melhorias no produto oferecido e nos serviços prestados, espera-se também poder medir esta conquista através dos índices de clientes. Para a fidelização dos clientes, propõe-se implantar um serviço pós-vendas, onde os clientes poderão demonstrar 
opiniões e sugestões sobre o produto e serviço oferecido a eles. Por fim, no objetivo de ser referência no mercado de revenda de óleo diesel se intenciona reavaliar o sistema de gestão empresarial para promover a aumento de participação de mercado.

\section{Perspectiva de Aprendizagem e Crescimento}

A perspectiva de Aprendizagem e Crescimento foi fundamentada pela essencialidade dos colaboradores na empresa. A necessidade de manter os funcionários capacitados e também satisfeitos originou à criação das perspectivas de aprendizagem e crescimento, considerando o reconhecimento de que o crescimento da empresa será possível uma vez que a mesma procurar atender as necessidades dos colaboradores.

O desenvolvimento de cursos e treinamentos será de grande importância para a empresa, pois, acredita-se que com profissionais instruídos e capacitados a empresa evitará muitos erros operacionais que são, na maioria das vezes, revertidos em prejuízos financeiros. O desempenho dos funcionários aumentaria e a empresa consequentemente cresceria.

Seguindo esta perspectiva, a satisfação dos colaboradores foi definida pela importância dos mesmos dentro das organizações. As metas e indicadores propostos partiram da necessidade dos colaboradores possuírem participações ativas dentro da organização. Por meio deste pensamento seria essencial a realização de reuniões participativas com a intenção de identificar quais as necessidades dos colaboradores, pois se entende que o total conhecimento da deficiência cada setor só pode ser conhecido por aqueles que ali operam.

Quadro 6: Perspectiva de Aprendizagem e Crescimento.

\begin{tabular}{|l|l|l|l|}
\hline \multicolumn{1}{|c|}{$\begin{array}{l}\text { Perspectiva de Aprendizagem e } \\
\text { Crescimento }\end{array}$} & \multicolumn{1}{c|}{ Metas } & \multicolumn{1}{c|}{ Ações } \\
\hline $\begin{array}{l}\text { Desenvolver a conscientização dos } \\
\text { colaboradores quanto ao } \\
\text { conhecimento total das normas } \\
\text { internas da empresa. }\end{array}$ & $\begin{array}{l}\text { Instruir os colaboradores } \\
\text { quanto as normas da } \\
\text { empresa. }\end{array}$ & $\begin{array}{l}\text { Propor cursos e treinamentos } \\
\text { internos. }\end{array}$ & $\begin{array}{l}\text { Redução de } \\
\text { advertências, multas } \\
\text { e acidentes. }\end{array}$ \\
\hline $\begin{array}{l}\text { Capacitar os funcionários em suas } \\
\text { áreas específicas. }\end{array}$ & $\begin{array}{l}\text { Aumenta o número de } \\
\text { funcionários com } \\
\text { capacitação. }\end{array}$ & $\begin{array}{l}\text { Fornecer cursos, treinamento e } \\
\text { incentivar formação de ensino } \\
\text { superior. }\end{array}$ & $\begin{array}{l}\text { Melhoria no } \\
\text { desempenho dos } \\
\text { colaboradores. }\end{array}$ \\
\hline Satisfação dos colaboradores. & $\begin{array}{l}\text { Agradar os } \\
\text { colaboradores. }\end{array}$ & $\begin{array}{l}\text { Realizar reuniões participativas } \\
\text { para conhecer as necessidades e } \\
\text { sugestões dos funcionários. }\end{array}$ & $\begin{array}{l}\text { Diminuição do índice } \\
\text { de rotatividade. }\end{array}$ \\
\hline
\end{tabular}

\section{Mapa Estratégico}

A partir das perspectivas anteriormente elaboradas e apresentadas, desenvolveu-se o Mapa Estratégico para a empresa em estudo, apresentado no Figura 2. A construção do mapa estratégico seguiu como propósito obedecer aos princípios ditados por Kaplan e Norton. Com base no que foi anteriormente comentado, o mapa estratégico é para as organizações um mapa a ser seguido, ele demonstra de forma clara e precisa quais os objetivos almejados, o que se necessita fazer para alcançar os mesmos e ainda esclarece que tudo isso, está baseado na missão, visão e valores da empresa. O mapa estratégico é, portanto, a visualização de fácil compreensão dos objetivos da empresa, permitindo que tanto os proprietários quanto 
aos colaboradores consigam entender quais os passos que precisam ser seguidos para a obtenção dos objetivos. A compreensão do que o mapa estabelece é fundamental, pois a participação de todos os envolvidos na empresa é parte indispensável para a concretização dos objetivos.

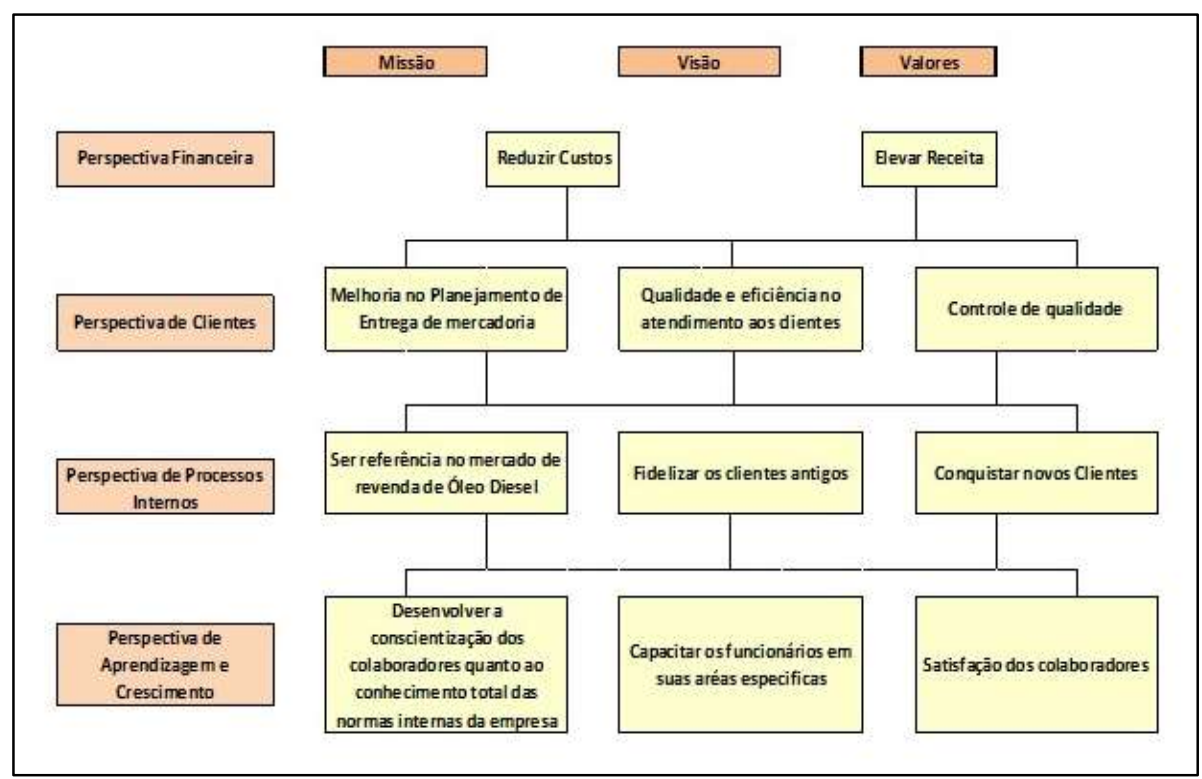

Quadro 2: Mapa Estratégico.

\section{CONCLUSÕES}

Este trabalho teve como objetivo apresentar uma proposta de implantação da ferramenta de gestão empresarial, BSC, a uma empresa do ramo de Transportador Revendedor Retalhista-TRR de Óleo Diesel. Diante da necessidade de continuidade no mercado as organizações buscam melhorias nos processos de gestão e mudanças para a sobrevivência no mercado altamente competitivo. O BSC por sua vez, possibilita às organizações melhoria no desempenho e no alcance dos seus objetivos.

Desta forma, o presente trabalho verificou quais os procedimentos necessários para implantação do BSC-BSC em uma TRR. Constatou-se que os procedimentos necessários confirmam a literatura, especialmente o que foi prescrito pelos criadores do BSC, Kaplan e Norton. O BSC, enquanto ferramenta de gestão, foi apresentado ao proprietário e ao gestor da empresa com sugestão para definição da missão, da visão e dos valores, assim como a identificação da estratégia empresarial, e ainda as perspectivas. Os mesmos concordaram em formular esses itens e receberam o mapa estratégico desenvolvido para a empresa.

Conclui-se que a pesquisa ofereceu à empresa a evidenciação da importância de melhorias no processo de gestão através do BSC, notadamente quanto à formulação de indicadores com enfoque nas quatro perspectivas do BSC. Como continuidade da pesquisa sugere-se efetuar um levantamento dos resultados gerados, através dos indicadores criados, comparando com o desempenho anterior para comprovar empiricamente a validade do BSC.

\section{REFERÊNCIAS}

ANP. Agência Nacional de Petróleo, Gás Natural e Biocombustíveis. Transportador Revendedor Retalhista (TRR). ANP, 2017.
BERTAGLIA, P. R.. Logística e gerenciamento da cadeia de abastecimento. Saraiva, 2017. 
BEUREN, I.. Como elaborar trabalhos monográficos em contabilidade. 3 ed. São Paulo: Atlas, 2010.

CHIAVENATO, I.; SAPIRO, A.. Planejamento Estratégico: fundamentos e aplicações. 2 ed. Rio de Janeiro: Elsevier, 2009.

CHIAVENATO, I.. Comportamento organizacional: a dinâmica do sucesso das organizações. Manole, 2005.

CORSATTO, C. A.; HOFFMANN, W. A. M.. Gestão do Conhecimento e Inteligência competitiva: delineamento de estratégias de competitividade e inovação para pequenas empresas. Encontros Bibli: Revista Eletrônica de Biblioteconomia e Ciência Da Informação, v.18, n.38, p.1936, 2013.

COSTA, A. P. P.. Balanced Scorecard. São Paulo: Atlas, 2008.

CREPALDI, S. A.. Contabilidade Gerencial: Teoria e prática. 6 ed. São Paulo: Atlas, 2012.

FISCHMANN, A.; ALMEIDA, M.. Planejamento estratégico na prática. São Paulo: Atlas, 2009.

FREIRE, R. P. A. S.; OLIVEIRA, K. P. S.; FERRAZ, R. C.. O clima organizacional e o balanced scorecard: uma evidência empírica no setor hoteleiro. In: CONGRESSO BRASILEIRO DE CUSTOS. Anais. 2010.

GALAS, E. S.; PONTE, V. M. R.. O Balanced Scorecard e o alinhamento estratégico da tecnologia da informação: um estudo de casos múltiplos. Revista Contabilidade $\boldsymbol{\&}$

Finanças, v.17, n.40, p.37-51, 2006. DOI: https://dx.doi.org/10.1590/S1519-70772006000100004

GOMES, C. C.; GOMES, L. S.. O uso de ferramentas de gestão na elaboração do planejamento estratégico. Revista Caribeña de Ciencias Sociales, 2015.

GOMES, P.; MENDES, S.; CARVALHO, J.. O Balanced Scorecard como instrumento de medida de desempenho das forças policiais - estudo de casos. Economia Global e Gestão, v.15, n.2, p.91-114, 2010.

IBGE. Instituto Brasileiro de Geografia e Estatística. Indicadores, Estática de produção agrícola. Rio de Janeiro: IBGE, 2017.

KAPLAN, R. S.; NORTON, D. P.. Organização orientada para a estratégia: como as empresas que adotam o balanced scorecard prosperam no novo ambiente de negócios. 6 ed. Rio de Janeiro: Campus, 2000.

KAPLAN, R. S.; NORTON, D. P.. A estratégia em ação: balanced scorecard. Rio de Janeiro: Elsevier, 1997.

LIMA, H. B. R.. Resolução ANP no 25, de 15.08.2007. Brasília: DOU, 2007.
LIMA, R. S.. Proposta de Modelo para Implementação de um Sistema de Indicadores de Desempenho. Dissertação (Mestrado em Engenharia) - Universidade de São Paulo, São Paulo, 2010.

LUNKES, R. J.; SCHNORRENBERGER, D.; GASPARETTO, V.; CAPARICA, C. E.. Implementação do Balanced Scorecard em uma empresa de software. Pensar Contábil, v.11, n.45, 2009.

MARCONI, M. A.; LAKATOS, E. M.. Fundamentos de metodologia cientifica: Técnicas de pesquisa. 7 ed. São Paulo: Atlas, 2010.

MOTTA, R.. A busca da competitividade nas empresas. Revista de Administração de empresas, v.35, n.2, p.12-16, 1995.

NIVEN, P.. Balanced Scorecard Step-By-Step for Government and Nonprofit Agencies. New Jersey: John Wiley \& Sons Inc., 2003.

OLIVEIRA, D. P. R.. Planejamento Estratégico: conceitos, metodologia e práticas. 31 ed. São Paulo: Atlas, 2013.

PORTER, M. E.. Estratégia Competitiva: técnicas para análise de indústrias e da concordância. 2 ed. Rio de Janeiro: Elsevier, 2004

PORTER, M. E.. Vantagem Competitiva: criando e sustentando um desempenho superior. Rio de Janeiro: Elsevier, 1989.

PRIETO, V. C.; PEREIRA, F. L. A.; CARVALHO, M. M.; LAURINDO, F. J. B.. Fatores Críticos na implementação do Balanced Scorecard. Gestão \& Produção, v.13, n.1, p.81-92, 2006.

RENESTO, J. C.. Aplicação do Balanced Scorecard na avaliação de desempenho em Hospitais. Dissertação (Mestrado em Ciências Contábeis e Atuária) - Universidade Católica de São Paulo, São Paulo, 2008.

ROCHA, I.; LAVARDA, C.. Retrospectiva bibliográfica sobre o balanced scorecard (BSC) como instrumento de planejamento e controle nas empresas. Revista de Contabilidade do Mestrado em Ciências Contábeis da UERJ, Rio de Janeiro, v.16, n.1, p.19-34, 2011.

SCHMIDT, L. F.; NALIN, J. A.. Balanced scorecard como ferramenta estratégica e competitiva aplicável a uma distribuidora de combustíveis. Cippus, v.1, n.2, p.23-48, 2012.

VIEIRA, R. P.. Balanced scorecard: o uso da perspectiva financeira na gestão estratégica e operacional em centro de diagnósticos. Dissertação (Mestrado em Ciência e Tecnologia em Saúde) - Universidade de Mogi das Cruzes, Mogi das Cruzes, 2017.

A CBPC - Companhia Brasileira de Produção Científica (CNPJ: 11.221.422/0001-03) detém os direitos materiais desta publicação. Os direitos referem-se à publicação do trabalho em qualquer parte do mundo, incluindo os direitos às renovações, expansões e disseminações da contribuição, bem como outros direitos subsidiários. Todos os trabalhos publicados eletronicamente poderão posteriormente ser publicados em coletâneas impressas sob coordenação da Sustenere Publishing, da Companhia Brasileira de Produção Científica e seus parceiros autorizados. Os (as) autores (as) preservam os direitos autorais, mas não têm permissão para a publicação da contribuição em outro meio, impresso ou digital, em português ou em tradução. 